\title{
Sonographic Evaluation of Site Specific Nerve Dimensions in Young Asymptomatic Adults: A Cross-sectional Study
}

\section{ABSTRACT}

Introduction: Tibial Nerve (TN) and Common Peroneal Nerve (CPN) supply the muscles and skin of lower extremity via their major branches and also send articular branches to the joints of lower extremity. Knowledge of nerve dimensions is useful for diagnosis of pathologies, planning nerve blocks, biopsies or other therapeutic procedures.

Aim: To assess bilateral Tibial Nerve (TN) and Deep Peroneal Nerve (DPN) morphology and morphometry at ankle through a sonographic evaluation.

Materials and Methods: A cross-sectional, observational study was conducted in the Department of Anatomy, King George's Medical University, Lucknow, Uttar Pradesh, India from September 2018 to August 2019. Morphology and morphometry of TN and DPN was observed by High Resolution Ultrasonography (HRUS) at specific anatomical site in 100 first year Bachelor in Medicine and Bachelor in Surgery (MBBS) students (50 males and 50 females). The nerve parameters like, Cross-sectional Area (CSA), nerve perimeter and depth from skin were measured and the data was analysed statistically. Among asymptomatic subjects, various nerve parameters and subcutaneous depth were observed in both genders to establish normal reference values for the purpose of creating database. The association of nerve parameter to Body Mass Index (BMI) was also studied. To compare the change in a parameter at two different time intervals, paired t-test was used. To test the significance of two means, the Student's t-test was used.

Results: Amongst the total 100 subjects, 50 were males and 50 females with age range 17-25 years. Mean CSA, perimeter and DFS (depth from skin) of TN was $9.6 \pm 1.02 \mathrm{~mm}^{2}, 9.95 \pm 0.78 \mathrm{~mm}$ and $9.7 \pm 1.13 \mathrm{~mm}$, respectively, whereas the DPN mean CSA, perimeter and subcutaneous depth was $8.0 \pm 1.05 \mathrm{~mm}^{2}$, $8.5 \pm 1.12 \mathrm{~mm}$ and $9.0 \pm 0.98 \mathrm{~mm}$, respectively. The CSA and perimeter of right TN was significantly $(p$-value $=0.004)$ greater than left. DPN mean CSA ( $p$-value $=0.008$ ) and perimeter ( $p$-value $<0.001$ ) were significantly greater on the right side in comparison to left. The TN was significantly deeper in location in females $(p<0.004)$. DPN was significantly deeper in females than males $(p<0.001)$. Differences in nerve parameters among subjects in relation to were insignificant.

Conclusion: Nerve parameters were conveniently measured by ultrasound. Knowledge of site-specific normal size of nerves is of great importance in diagnosing various neuropathies, compression syndromes and traumatic nerve lesions. In current study, we have attempted to create a reference database that may be valuable for neurologists as well as radiologists. Knowledge of nerve depth and location may help in guiding ankle blocks in various surgeries and for other diagnostic and therapeutic purposes.

\section{INTRODUCTION}

The TN and CPN supply the muscles and skin of lower extremity via their major branches and also send articular branches to the joints of lower extremity. TN is derived from anterior divisions of sacral plexus and is the nerve of the posterior compartment of lower extremity. It descends along the posterior thigh and popliteal fossa; continues its course down the leg posterior to the tibia and during its descent supplies the deep muscles of the posterior leg. In its course in the popliteal fossa, it is related to the popliteal vessels and in leg, it descends with the posterior tibial vessels [1]. At the ankle, it passes posterior and inferior to the medial malleolus through the tarsal tunnel, covered superiorly by the flexor retinaculum. Within this tunnel, it gives off cutaneous branches to the heel. In the foot, tendon of flexor hallucis longus and posterior tibial artery are anterior to the nerve. TN can be easily located just proximal to the medial malleolus for a regional nerve block [2-4]

The deep fibular nerve begins in the lateral compartment, deep to the fibularis longus as one of the two divisions of the common fibular nerve (previously called the DPN). It continues around the fibular neck, pierces the anterior intermuscular septum, and runs obliquely forward between the extensor digitorum longus and tibialis anterior on the interosseous membrane, where it lies with the anterior tibial artery. Approximately, 3 to $5 \mathrm{~cm}$ above the ankle joint, the DPN courses between the extensor digitorum longus and extensor hallucis longus; lateral to the anterior tibial artery [5]. It descends in close relation to the anterior tibial artery to reach the ankle, where it usually terminates by dividing into medial and lateral branches. Through its articular branches, the DPN supplies the ankle joint and tarsal and metatarsophalangeal joints of the medial four toes of the foot. Cutaneous branches provide sensory supply to the skin of the first web space $[6,7]$.

Deep peroneal neuropathy is seen among athletes, skiers with tight-fitting ski boots, soccer players receiving repetitive blows to the dorsum of the foot, and ballet dancers, who have prominent dorsal ridge of the joints that compress the nerve when they go up on point position [8-10]. Variations in nerve anatomy have been reported in previous literature. Anatomical variations may cause errors in establishing the correct diagnosis and variations in nerve termination have been suspected as a possible cause for incomplete block at the ankle [11]

HRUS allows visualisation of nerve caliber, continuity, echogenicity, echotexture, is able to identify tumours, traumatic lesions, nerve entrapment, inflammation demyelinating features or infections and has become a preferred technique for peripheral nerve imaging. 
Nerve blocks, biopsies or therapeutic procedures can be performed with ease through ultrasound guided interventions.

The aim of the study was to observe bilateral tibial and bilateral DPN parameters (cross-sectional area, perimeter) and subcutaneous depth (depth from skin) at ankle in young adult males and females to establish normal reference values and also to associate Crosssectional Area (CSA) to Body Mass Index (BMI).

\section{MATERIALS AND METHODS}

A cross-sectional, observational study was conducted in the Department of Anatomy, King George's Medical University, Lucknow, Uttar Pradesh, India from September 2018 to August 2019. Ethical approval for the study was obtained from the University Ethical Committee (Ethical Review Board's reference code no.- 93 rd ECM II B-Thesis/P6). The study participants included student volunteers among first year Bachelor in Medicine and Bachelor in Surgery (MBBS) students. The students were explained about the procedure, 100 students (50 male \& 50 female students) who were willing to participate in the study were selected and informed consent was obtained from them.

Inclusion criteria: The first year MBBS students who gave their consent to participate in study after explaining about the procedure, were included in the study.

Exclusion criteria: All those students who complained of symptoms like numbness, tingling, painful sensations, muscle weakness, twitching, abnormal limb movement, or balance problem either at the time of study or in the past were excluded from the study.

\section{Procedure}

Ultrasonography was carried out using Esaote Europe My Lab 40 ultrasound machine with linear probe of frequency $6-13 \mathrm{MHz}$. Ultrasound of nerve was performed with the subjects in a supine position with leg in extension. Skin and transducer preparation was done, nerves were identified at the predetermined sites and traced distally and proximally. TN was localised at ankle $3 \mathrm{~cm}$ proximal to the medial malleolus just posterior to the tibial artery [Table/Fig-1,2]
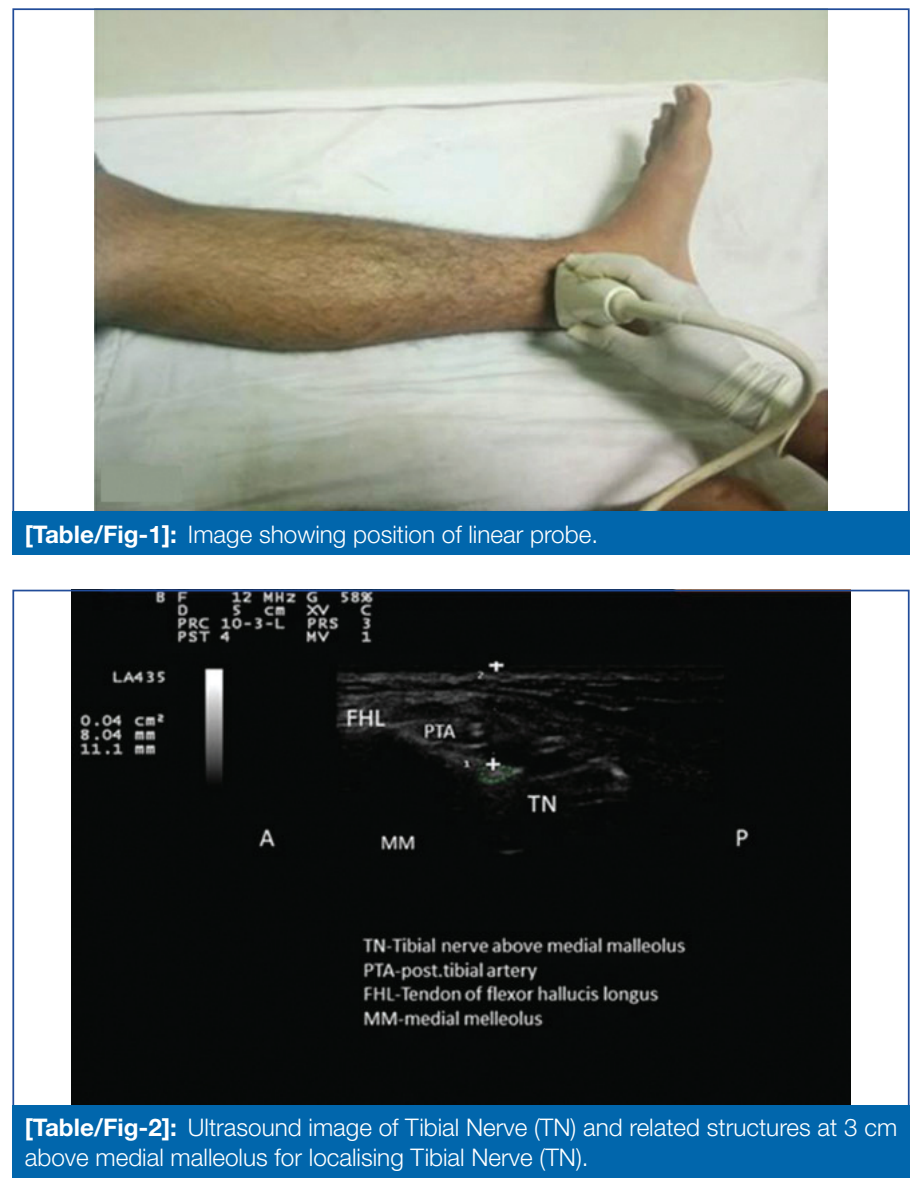

and DPN was localised $3 \mathrm{~cm}$ proximal to the superior extensor retinaculum [Table/Fig-3,4].
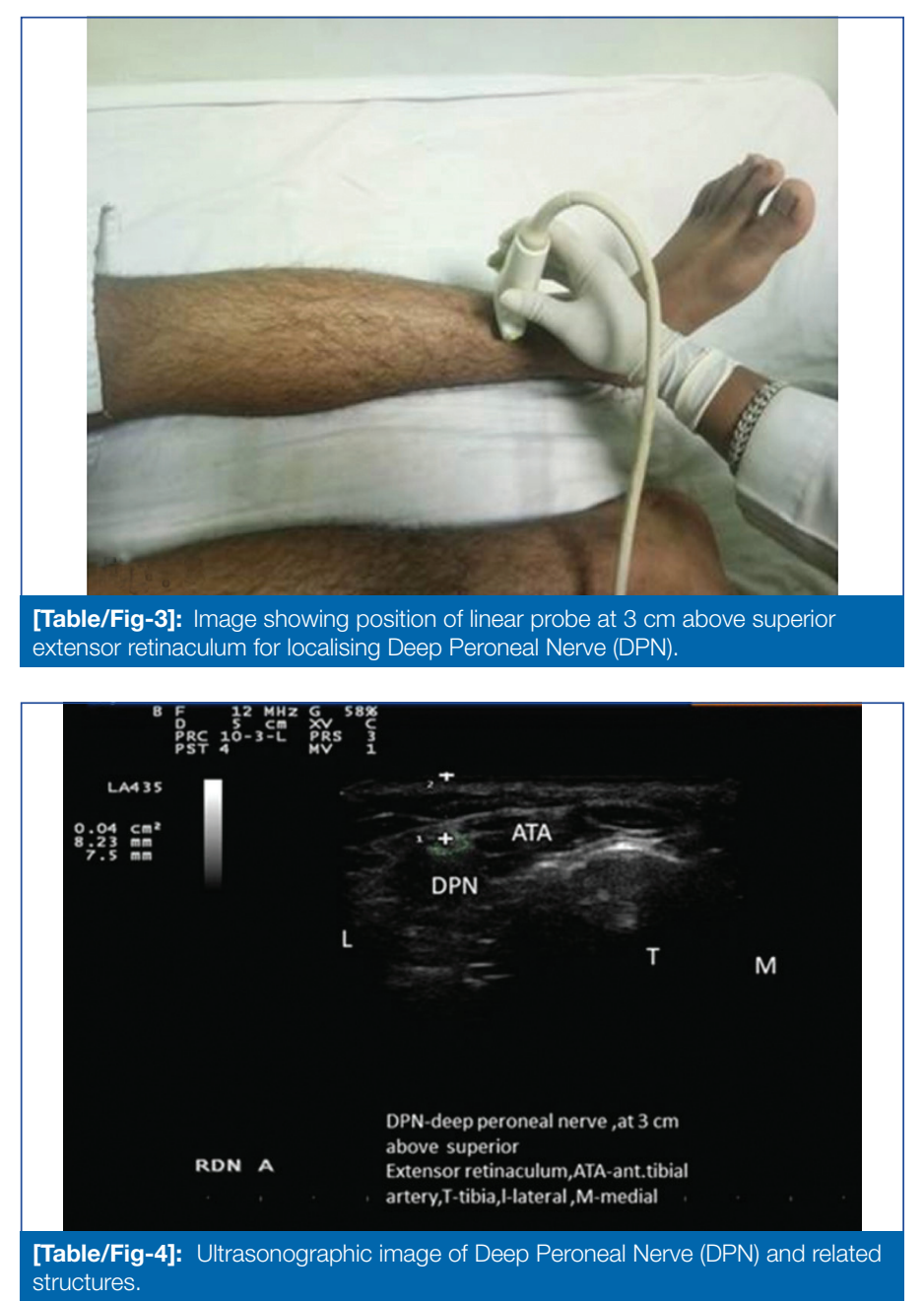

Nerves were differentiated from surrounding structures and identified on the basis of characteristic echo pattern, described as, "honeycomb shaped" because of dark punctuate areas (fascicle groups) surrounded by hyperechoic band (perineurium). In longitudinal plane, they were seen as a long, slim structure with parallel hypoechoic and hyperechoic lines [12].

At each site, the CSA, perimeter and subcutaneous depth of Tibial and DPN were measured and recorded. During the tracing of nerve and taking measurements, care was taken to ensure that the transducer was perpendicular to nerve and measurements were taken excluding the echogenic rim [13]. Age, sex, height and weight were noted and subsequently BMl was calculated using formula, $\mathrm{BMl}=$ weight $(\mathrm{Kg}) /$ height $\left(\mathrm{m}^{2}\right)$ for each participant. All the readings were recorded by a single observer carefully. The observed measurements were compared between the left and right side and also among genders.

\section{STATISTICAL ANALYSIS}

The statistical analysis was done using Statistical Package for Social Sciences (SPSS) version 21.0 statistical analysis software. The values were represented in number $(n)$, percentage (\%) and mean $\pm S D$. To compare the change in a parameter at two different time intervals, Paired t-test was used. To test the significance of two means, the Student's t-test was used. The $\mathrm{p}$-value $<0.05$ was considered to be significant.

\section{RESULTS}

Total of 100 first year MBBS students were included, 50 males and 50 females. The age range of all the subjects was 1725 years. Overall mean CSA, perimeter and subcutaneous depth 
(depth from skin) of TN was $9.6 \pm 1.02 \mathrm{~mm}^{2}, 9.95 \pm 0.78 \mathrm{~mm}$ and $9.7 \pm 1.13 \mathrm{~mm}$, respectively, whereas the DPN mean CSA, perimeter and subcutaneous depth was $8.0 \pm 1.05 \mathrm{~mm}^{2}, 8.5 \pm 1.12 \mathrm{~mm}$ and $9.0 \pm 0.98 \mathrm{~mm}$, respectively [Table/Fig-5].

In right TN, mean CSA and perimeter were found to be greater and their difference was significant [Table/Fig-6].

\begin{tabular}{|l|c|c|}
\hline Variables & $\begin{array}{c}\text { Tibial nerve } \\
\text { (Mean } \pm \text { SD) }\end{array}$ & $\begin{array}{c}\text { Deep peroneal nerve } \\
\text { (Mean } \pm \text { SD) }\end{array}$ \\
\hline CSA $\left(\mathrm{mm}^{2}\right)$ & $9.60 \pm 1.02$ & $8.0 \pm 1.05$ \\
\hline Perimeter $(\mathrm{mm})$ & $9.95 \pm 0.78$ & $8.50 \pm 1.12$ \\
\hline DFS $(\mathrm{mm})$ & $9.70 \pm 1.13$ & $9.0 \pm 0.98$ \\
\hline
\end{tabular}

[Table/Fig-5]: Mean cross-sectional area, perimeter and depth of tibial (TN) and Deep Peroneal Nerves (DPN) at ankle.

CSA: Cross-sectional area; DFS: Depth from skin

\begin{tabular}{|c|c|c|c|c|c|c|c|c|c|}
\hline \multirow{2}{*}{$\begin{array}{l}\text { Parameters } \\
\text { assessed }\end{array}$} & \multicolumn{4}{|c|}{ Right TN $(\mathrm{N}=100)$} & \multicolumn{4}{|c|}{ Left TN $(N=100)$} & \multirow{2}{*}{$\begin{array}{l}{ }^{*} \mathrm{p}- \\
\text { value }\end{array}$} \\
\hline & Min. & Max. & Mean & SD & Min. & Max. & Mean & SD & \\
\hline $\mathrm{CSA}\left(\mathrm{mm}^{2}\right)$ & 6.0 & 12.0 & 9.3 & 1.00 & 5.0 & 12.0 & 8.8 & 1.45 & $<0.004$ \\
\hline $\begin{array}{l}\text { Perimeter } \\
(\mathrm{mm})\end{array}$ & 6.2 & 12.1 & 10.3 & 0.96 & 5.1 & 11.9 & 10.1 & 1.09 & $<0.004$ \\
\hline DFS (mm) & 7.6 & 11.8 & 9.9 & 1.13 & 7.2 & 12.0 & 9.8 & 1.22 & 0.155 \\
\hline \multicolumn{10}{|c|}{$\begin{array}{l}\text { [Table/Fig-6]: Differences in Tibial Nerve (TN) parameters at ankle on the basis of } \\
\text { laterality; p-value <0.05 was considered to be significant. } \\
\text { CSA: Cross sectional area; DFS: Depth from skin; Rt: Right; Lt: Left; TN: Tibial nerve; "paired t-test } \\
\text { SD: Standard deviation }\end{array}$} \\
\hline
\end{tabular}

In males, mean TN CSA and perimeter was observed to be insignificantly greater but the nerves were found subcutaneously deeper in females. The difference in nerve depth among males and females was significant [Table/Fig-7].

In right DPN, mean CSA and perimeter was greater as compared to the left, and the right nerve was observed to be more superficially placed. Difference in CSA ( $p$-value=0.008) and perimeter ( $p$-value $<0.001$ ) between the nerves of the right and left side was significant, but the difference in subcutaneous depth of right and left nerves was insignificant ( $p$-value=0.111) [Table/Fig-8].

In males, DPN mean CSA on right side was $7.1 \pm 1.12 \mathrm{~mm}^{2}$ and left side was $6.2 \pm 0.92 \mathrm{~mm}^{2}$, perimeter on right was $8.7 \pm 1.32 \mathrm{~mm}$ and on left side was $7.6 \pm 1.01 \mathrm{~mm}$ and depth of DPN on right side was $8.2 \pm 1.04 \mathrm{~mm}$ and on left side was $8.0 \pm 1.64 \mathrm{~mm}$. In females, DPN mean CSA on right side was $6.2 \pm 1.80 \mathrm{~mm}^{2}$ and left side was $5.1 \pm 1.58 \mathrm{~mm}^{2}$, perimeter on right side was $8.6 \pm 1.43 \mathrm{~mm}$ and on left side was $7.3 \pm 1.41 \mathrm{~mm}$ and depth of DPN of right side was $8.6 \pm 1.08 \mathrm{~mm}$ and of left side was $8.7 \pm 1.28 \mathrm{~mm}$. DPN was deeper in females than males and the difference was statistically significant [Table/Fig-9].

Among the study subjects, 16 subjects were underweight, 72 weighed normal, 10 included overweight and 2 were obese individuals. For the purpose of analysis, overweight and obese were clubbed together as number of obese subjects was very less. On comparing, the nerve dimensions among different subjects as per BMI, TN mean CSA and perimeter was similar in underweight and normal individuals whereas it was insignificantly greater in overweight subjects. No difference was observed in DPN mean CSA in those with normal weight and those who were obese; whereas mean CSA of DPN was observed lower in the subjects who were underweight [Table/Fig-10,11].

\section{DISCUSSION}

In the present study, tibial nerve's CSA at ankle was $9.6 \pm 1.02 \mathrm{~mm}^{2}$ (range $=5.0$ to $12 \mathrm{~mm}^{2}$ ). Cartwright $\mathrm{MS}$ et al., evaluated TN at the ankle and reported CSA as $13.7 \pm 4.3 \mathrm{~mm}^{2}$ [5], Lee D and Dauphinee DM reported mean CSA of TN as $12.0 \mathrm{~mm}^{2}$, Seok $\mathrm{HY}$ et al., observed that CSA was $12.1 \pm 3.1 \mathrm{~mm}^{2}$, Singh $\mathrm{S}$ et al.,

\begin{tabular}{|c|c|c|c|c|c|c|c|c|c|c|c|c|}
\hline \multirow{3}{*}{$\begin{array}{l}\text { Values } \\
\text { analysed }\end{array}$} & \multicolumn{6}{|c|}{ Right TN } & \multicolumn{6}{|c|}{ Left TN } \\
\hline & \multicolumn{2}{|c|}{$\mathrm{CSA}\left(\mathrm{mm}^{2}\right)$} & \multicolumn{2}{|c|}{ Perimeter $(\mathrm{mm})$} & \multicolumn{2}{|c|}{ DFS (mm) } & \multicolumn{2}{|c|}{$\mathrm{CSA}\left(\mathrm{mm}^{2}\right)$} & \multicolumn{2}{|c|}{ Perimeter $(\mathrm{mm})$} & \multicolumn{2}{|c|}{ DFS (mm) } \\
\hline & M & $\mathrm{F}$ & M & $\mathrm{F}$ & $M$ & $\mathrm{~F}$ & M & $\mathrm{F}$ & M & $\mathrm{F}$ & M & $\mathrm{F}$ \\
\hline Minimum & 6.0 & 6.0 & 8.02 & 6.2 & 8.0 & 7.6 & 6.0 & 5.0 & 8.1 & 8.0 & 7.3 & 7.2 \\
\hline Maximum & 12.0 & 12.0 & 11.8 & 12.1 & 10.8 & 11.8 & 11.0 & 12.0 & 11.9 & 11.5 & 10.2 & 12.0 \\
\hline Mean & 8.9 & 8.4 & 9.8 & 9.1 & 9.7 & 9.9 & 8.6 & 8.0 & 9.5 & 9.0 & 8.7 & 9.2 \\
\hline $\begin{array}{l}\text { Standard } \\
\text { Deviation }\end{array}$ & 1.38 & 1.32 & 1.92 & 1.90 & 1.62 & 1.62 & 1.32 & 1.50 & 1.34 & 1.32 & 0.69 & 1.21 \\
\hline${ }^{*} \mathrm{p}$-value & \multicolumn{2}{|c|}{0.431} & \multicolumn{2}{|c|}{0.492} & \multicolumn{2}{|c|}{0.004} & \multicolumn{2}{|c|}{0.422} & \multicolumn{2}{|c|}{0.438} & \multicolumn{2}{|c|}{0.004} \\
\hline
\end{tabular}

\begin{tabular}{|c|c|c|c|c|c|c|c|c|c|}
\hline \multirow[b]{2}{*}{ Parameters analysed } & \multicolumn{4}{|c|}{ Right DPN (N=100) } & \multicolumn{4}{|c|}{ Left DPN ( $N=100)$} & \multirow[b]{2}{*}{${ }^{*} \mathrm{p}$-value } \\
\hline & Min. & Max. & Mean & SD & Min. & Max. & Mean & SD & \\
\hline $\mathrm{CSA}\left(\mathrm{mm}^{2}\right)$ & 5.0 & 10.0 & 7.9 & 1.05 & 3.0 & 9.0 & 6.5 & 1.12 & $<0.008$ \\
\hline Perimeter (mm) & 5.3 & 11.1 & 9.1 & 1.17 & 5.1 & 10.0 & 8.4 & 1.06 & $<0.001$ \\
\hline DFS (mm) & 6.4 & 10.9 & 8.8 & 1.00 & 7.0 & 10.2 & 9.0 & 1.17 & 0.111 \\
\hline
\end{tabular}

[Table/Fig-8]: Deep Peroneal Nerve (DPN) parameters at right and left ankle, $3 \mathrm{~cm}$ proximal to superior extensor retinaculum; $p$-value $<0.05$ was considered to be significant. CSA: Cross sectional area; DFS: Depth from skin; Rt: Right, Lt.: Left; TN: Tibial nerve; " ${ }^{*}$ aired t-test

\begin{tabular}{|c|c|c|c|c|c|c|c|c|c|c|c|c|}
\hline \multirow{3}{*}{$\begin{array}{l}\text { Values } \\
\text { analysed }\end{array}$} & \multicolumn{6}{|c|}{ Right DPN } & \multicolumn{6}{|c|}{ Left DPN } \\
\hline & \multicolumn{2}{|c|}{$\mathrm{CSA}\left(\mathrm{mm}^{2}\right)$} & \multicolumn{2}{|c|}{ Perimeter $(\mathrm{mm})$} & \multicolumn{2}{|c|}{ DFS (mm) } & \multicolumn{2}{|c|}{$\mathrm{CSA}\left(\mathrm{mm}^{2}\right)$} & \multicolumn{2}{|c|}{ Perimeter $(\mathrm{mm})$} & \multicolumn{2}{|c|}{ DFS (mm) } \\
\hline & $M$ & $\mathrm{~F}$ & $M$ & $F$ & M & $F$ & $M$ & $F$ & $M$ & $F$ & $M$ & $F$ \\
\hline Minimum & 5.0 & 4.0 & 6.5 & 5.3 & 6.4 & 6.4 & 5.0 & 3.0 & 5.1 & 5.2 & 7.4 & 7.0 \\
\hline Maximum & 9.0 & 10.0 & 10.5 & 11.1 & 9.5 & 10.9 & 8.0 & 9.0 & 9.8 & 10.0 & 9.5 & 10.2 \\
\hline Mean & 7.1 & 6.2 & 8.7 & 8.6 & 8.2 & 8.6 & 6.2 & 5.1 & 7.6 & 7.3 & 8.0 & 8.7 \\
\hline $\begin{array}{l}\text { Standard } \\
\text { deviation }\end{array}$ & 1.12 & 1.80 & 1.32 & 1.43 & 1.04 & 1.08 & 0.92 & 1.58 & 1.01 & 1.41 & 1.64 & 1.28 \\
\hline${ }^{*} \mathrm{p}$-value & \multicolumn{2}{|c|}{0.016} & \multicolumn{2}{|c|}{0.014} & \multicolumn{2}{|c|}{$<0.001$} & \multicolumn{2}{|c|}{0.015} & \multicolumn{2}{|c|}{0.016} & \multicolumn{2}{|c|}{$<0.001$} \\
\hline
\end{tabular}




\begin{tabular}{|l|l|c|c|c|c|c|c|}
\hline \multirow{2}{*}{ Peripheral nerve } & \multicolumn{2}{|l|}{ Under weight } & \multicolumn{2}{|c|}{ Normal } & \multicolumn{2}{c|}{$\begin{array}{c}\text { Over } \\
\text { weight+obese }\end{array}$} & *p-value \\
\cline { 2 - 8 } & Mean & SD & Mean & SD & Mean & SD & 'p' \\
\hline
\end{tabular}

\section{Tibial nerve}

\begin{tabular}{|l|c|c|c|c|c|c|c|}
\hline CSA & 9.4 & 2.2 & 9.4 & 6.1 & 9.6 & 1.5 & 0.971 \\
\hline Perimeter & 10.14 & 2.20 & 10.01 & 1.51 & 10.55 & 1.31 & 0.120 \\
\hline
\end{tabular}

Deep peroneal nerve

\begin{tabular}{|l|c|c|c|c|c|c|c|}
\hline CSA & 5.8 & 1.6 & 6.4 & 1.6 & 6.4 & 1.6 & 0.528 \\
\hline Perimeter & 7.60 & 1.58 & 7.65 & 1.52 & 7.50 & 1.68 & 0.852 \\
\hline
\end{tabular}

[Table/Fig-10]: Comparison of cross-sectional area and perimeter on the basis of Body Mass Index.

*Student's t-test

\begin{tabular}{|l|c|c|c|c|c|c|c|c|}
\hline \multirow{2}{*}{$\begin{array}{l}\text { Peripheral } \\
\text { nerve }\end{array}$} & \multirow{2}{*}{$\begin{array}{c}\text { Under } \\
\text { weight }\end{array}$} & \multicolumn{2}{c|}{ Normal } & \multicolumn{2}{c|}{$\begin{array}{c}\text { Over } \\
\text { weight+Obese }\end{array}$} & p-value \\
\cline { 3 - 10 } & Mean & SD & Mean & SD & Mean & SD & 'p' \\
\hline Tibial nerve & At ankle & 8.96 & 0.90 & 9.28 & 1.07 & 9.59 & 1.31 & 0.139 \\
\hline $\begin{array}{l}\text { Deep peroneal } \\
\text { nerve }\end{array}$ & At ankle & 8.37 & 0.73 & 8.30 & 0.82 & 8.48 & 0.72 & 0.454 \\
\hline
\end{tabular}

[Table/Fig-11]: BMI wise comparison of depth of peripheral nerves.

Student t-test was used

observed CSA in 58 subjects and it was $12.4 \pm 10.1 \mathrm{~mm}^{2}$ and Bedewi MA et al., studied 69 subjects and observed the mean value of $12.7 \pm 4.5 \mathrm{~mm}^{2}$ at ankle [5,14-17]. Kerasnoudis $A$ et al., observed CSA of TN as $6.36 \pm 1.45 \mathrm{~mm}^{2}$, Ito $T$ et al., studied TN in 35 healthy individuals and reported mean CSA as $7.2 \mathrm{~mm}^{2}$; Watanabe $T$ et al., conducted study on 20 healthy volunteers and gave mean CSA of TN as $8.9 \pm 2.8 \mathrm{~mm}^{2}$; and Uceyler $\mathrm{N}$ et al., studied 26 subjects ultrasonographically and observed that CSA of TN was $3.5 \pm 0.9 \mathrm{~mm}^{2}$ at ankle, much less than that found in the present study [13,18-20]. Tagliafico A et al., observed CSA of the TN at the ankle as $9.6 \mathrm{~mm}^{2}$ and Boehm $\mathrm{J}$ et al., observed 56 subjects ultrasonographically and gave mean value $9.6 \pm 2.2 \mathrm{~mm}^{2}$ which was nearly similar to our study $[21,22]$. Difference in values within various study groups could be due to difference in the technique and method used for taking measurement or difference in geographical location of study groups.

Tibial nerve's CSA was greater in males as compared to females, but the difference was found to be insignificant ( $p$-value $<0.431)$. Similar to present study Kerasnoudis A et al., also found CSA of TN higher in males as compared to females at ankle in German population [13]. Even after a meticulous and thorough search of literature, we were unable to find studies reporting perimeter and depth of TN at ankle or studies reporting CSA, perimeter and depth from skin of DPN for each side therefore, we were unable to compare the data of the present study.

In the present study, we found that right limb CSA, perimeter and depth obtained from HRUS were significantly greater than left limb. Nerve CSA and perimeter were greater in males as compared to females while bilateral nerves were subcutaneously deeper in females than males. Greater CSA and perimeter in males could be correlated to greater muscle mass in males as compared to females whereas greater depth in females could be due to greater subcutaneous fat in females. Future studies may be conducted to correlate these variables to nerve dimensions. Because of the unavailability of other studies reporting the perimeter of DPN, we could not compare these findings with that of other authors.

Though the mean CSA of TN as well as DPN was slightly greater in overweight as compared to underweight subjects, yet, differences in mean CSA and perimeter among underweight, normal weight and overweight subjects were insignificant. Previous authors have reported a correlation of BMl with nerve size [17]. The clinical importance of peripheral regional anaesthesia is rapidly growing. Today, peripheral nerve blocks are being used to manage a large spectrum of surgical and pain-related cases. Success rates and safety measures in daily clinical practice are the most important prerequisites for the use of peripheral regional anaesthesia, and are closely related to the administered volumes of local anaesthetics. Direct ultrasonographic visualisation of nerve structures facilitates the performance of blocks with reduced volumes of local anaesthetics [23]. USG guided evaluation of various parameters of peripheral nerves are also useful in leprosy, diabetic neuropathy, nerve tumours and peripheral neuropathies.

From the current discussion about CSA, perimeter and depth of nerves at different sites, it was realised that the knowledge of site specific size of nerves, is of great importance in diagnosing various neuropathies, compression syndromes and traumatic nerve lesions. The site specific dimensions of nerves could be used as control while comparing for any evaluation as a part of diagnosis or followup. Increased nerve size (diffuse or focal) and type of architectural pattern can clearly identify entrapment, compression and trauma. In the current study, we have attempted to create a site specific reference data that will be valuable for neurologists as well as radiologists for correct diagnosis of cases.

\section{Limitation(s)}

The present study was conducted on a small group of participants which were young individuals and the age of study subjects ranged within 17-25 years. The height and weight of subjects did not show a wide variation. Nerve dimensions were not studied in correlation to other variables like muscle mass, subcutaneous body fat etc.

\section{CONCLUSION(S)}

Nerve dimensions can be conveniently studied by ultrasound and are of importance to neurologists, radiologists, anaesthetists and surgeons. Nerve dimensions and nerve depths vary significantly between males and females. Ultrasonography guided evaluation of various parameters of peripheral nerves which are site specific as well as gender specific may be useful for nerve blocks, and for diagnosing nerve entrapment syndromes, traumatic lesions, leprosy, diabetic neuropathy, nerves tumours and peripheral neuropathies.

\section{Acknowledgement}

We would like to thank all faculty members of the department for their great support.

Author contributions: SS, JC and GS helped with the project developement; SS and KP helped with the data collection; SS, AR, GS, AR and MS helped with the data analysis; SS, AR, GS, AR and $\mathrm{JC}$ helped with Manuscript writing and editing.

\section{REFERENCES}

[1] Standring S. Gray's Anatomy.The Anatomical Basis of Clinical Practice. $3^{\text {th }}$ edition. Churchill Livingstone: Elsevier, 2004, Pp. 857-932.

[2] Benson E, Conroy C, Hoyt DB, Eastman AB, Pacyna S, Smith J, et al. Calcaneal fractures in occupants involved in severe frontal motor vehicle crashes. Accid Anal Prev. 2007;39(4):794-99.

[3] Veltman ES, Doornberg JN, Stufkens SA, Luitse JSK, van den Bekerom MPJ. Long-term outcomes of 1,730 calcaneal fractures: Systematic review of the literature. J Foot Ankle Surg. 2013;52(4):486-90.

[4] Wedmore I, Young S, Franklin J. Emergency department evaluation a management of foot and ankle pain. Emerg Med Clin North Am. 2015;33(2):363-96.

[5] Cartwright MS, Passmore LV, Yoon JS, Brown ME, Caress JB, Walker FO. Cross-sectional area reference values for nerve ultrasonography. Muscle Nerve. 2008;37(5):566-71

[6] Kennedy JG, Brunner JB, Bohne WH, Hodgkins CW, Baxter DB. Clinical importance of the lateral branch of the deep peroneal nerve. Clin Orthop Relat Res. 2007;459:222-28. Doi: 10.1097/BLO.0b013e31803c2fa2.

[7] Lawrence SJ, Botte MJ. The deep peroneal nerve in the foot and ankle: An anatomic study. Foot Ankle Int. 1995;16(11):724-28.

[8] Delfaut EM, Demondion X, Bieganski A, Thiron MC, Mestdagh H, Cotten A. Imaging of foot and ankle nerve entrapment syndromes: From well-demonstrated to unfamiliar sites. Radiographics. 2003;23(3):613-23.

[9] McCrory P, Bell S, Bradshaw C. Nerve entrapments of the lower leg, ankle and foot in sport. Sports Med. 2002;32(6):371-91.

[10] Schon LC. Nerve entrapment, neuropathy, and nerve dysfunction in athletes. Orthop Clin North Am. 1994;25(1):47-59. 
[11] Sunderland S. (ed.) The sciatic nerve and its tibial and common peroneal divisions: Anatomical and physiological features. In: Nerves and nerve injuries. Churchill Livingstone, New York, 1978, Pp. 925-66.

[12] Cartwright MS, Chloros GD, Walker FO, Wiesler ER, Campbell WW. Diagnostic ultrasound for nerve transection. Muscle Nerv. 2007;35(6):796-99.

[13] Kerasnoudis A, Pitarokoili K, Behrendt V, Gold R, Yoon MS. Cross-sectional area reference values for sonography of peripheral nerves and brachial plexus. Clin Neurophysiol. 2013;124(9):1881-88.

[14] Lee D, Dauphinee DM. Morphological and functional changes in the diabetic peripheral nerve: Using diagnostic ultrasound and neurosensory testing to select candidates for nerve decompression. J Am Podiatr Med Assoc. 2005;95(5):433-37.

[15] Seok HY, Jang JH, Won SJ, Yoon JS, Park KS, Kim BJ. Cross-sectional area reference values of nerves in the lower extremities using ultrasonography. Muscle Nerve. 2014;50(4):564-70.

[16] Singh S, Gupta K, Kaur S. High resolution ultrasonography of the tibial nerve in diabetic peripheral neuropathy. J Ultrason. 2017;17(71):246-52.

[17] Bedewi MA, Abodonya A, Kotb M, Kamal S, Mahmoud G, Aldossari K, et al. Estimation of ultrasound reference values for the lower limb peripheral nerves in adults: A cross-sectional study. Medicine. 2018;97(12):179-80.
[18] Ito T, Kijima M, Watanabe T, Sakuta M, Nishiyama K. Ultrasonography of the tibial nerve in vasculitic neuropathy. Muscle Nerve. 2007;35(3):379-82.

[19] Watanabe T, Ito $H$, Sekine A, Katano $Y$, Nishimura T, Kato $Y$, et al. Sonographic evaluation of the peripheral nerve in diabetic patients: The relationship between nerve conduction studies, echo intensity, and cross-sectional area. J Ultrasound Med. 2010;29(5):697-708.

[20] Uceyler N, Schafer KA, Meckenrodt D, Sommer C, Mullges W. High-resolution ultrasonography of the superficial peroneal motor and sural sensory nerves may be a non-invasive approach to the diagnosis of vasculitic neuropathy. Front Neurol. 2016;7:48. https://doi.org/10.3389/fneur.2016.00048.

[21] Tagliafico A, Cadoni A, Fisci E, Bignotti B, Padua L, Martinoli C. Reliability of sideto-side ultrasound cross-sectional area measurements of lower extremity nerves in healthy subjects. Muscle Nerve. 2012;46(5):717-22.

[22] Boehm J, Scheidl E, Bereczki D, Schelle T, Arányi Z. High-resolution ultrasonography of peripheral nerves: Measurements on 14 nerve segments in 56 healthy subjects and reliability assessments. Ultraschall Med. 2014;35(5):459-67.

[23] Oberndorfer U, Marhofer P, Bösenberg A, Willschke H, Felfernig M, Weintraud M, et al. Ultrasonographic guidance for sciatic and femoral nerve blocks in children Br J Anaesth. 2007;98(6):797-801.

\section{PARTICULARS OF CONTRIBUTORS:}

1. Senior Resident, Department of Anatomy, Krishna Mohan Medical College, Mathura, Uttar Pradesh, India.

2. Professor, Department of Anatomy, King George's Medical University, Lucknow, Uttar Pradesh, India.

3. Associate Professor, Department of Anatomy, King George's Medical University, Lucknow, Uttar Pradesh, India.

4. Professor, Department of Anatomy, King George's Medical University, Lucknow, Uttar Pradesh, India.

5. Professor, Department of Anatomy, King George's Medical University, Lucknow, Uttar Pradesh, India.

6. Associate Professor, Department of Anatomy, Government Medical College, Banda, Uttar Pradesh, India.

7. Senior Resident, Department of Anatomy, Ram Manohar Lohia Medical College, Lucknow, Uttar Pradesh, India.

\section{NAME, ADDRESS, E-MAIL ID OF THE CORRESPONDING AUTHOR:}

Garima Sehgal,

Associate Professor, Department of Anatomy, King George's Medical University,

Shahmina Road, Chowk, Lucknow, Uttar Pradesh, India.

E-mail: drgarimabhasin@gmail.com
PLAGIARISM CHECKING METHODS: [Jain Het al.]

- Plagiarism X-checker: Apr 29, 2021

- Manual Googling: Oct 06, 2021

- iThenticate Software: Oct 23, 2021 (15\%)

\section{AUTHOR DECLARATION:}

- Financial or Other Competing Interests: None

- Was Ethics Committee Approval obtained for this study? Yes

- Was informed consent obtained from the subjects involved in the study? Yes

- For any images presented appropriate consent has been obtained from the subjects. Yes

Date of Submission: Apr 28, 2021

Date of Peer Review: Jun 17, 2021

Date of Acceptance: Oct 12, 2021

Date of Publishing: Jan 01, 2022 